\title{
La biblioteca del predicador Pere Dorchal (+1419)
}

\section{The Library of the Preacher Pere Dorchal $(+1419)$}

\author{
Ma Rosario Ferrer Gimeno \\ Universitat de València \\ rosario.ferrer@uv.es
}

Recibido: 09/02/2015

Aceptado: 01/07/2015

\section{RESUMEN}

A partir del inventario post mortem de los libros de Pere Dorchal, sacerdote beneficiado en la catedral de Valencia, datado en 1419, se estudia la composición de la biblioteca de un predicador. Al mismo tiempo, se recompone su biografía.

Palabras clave: Pere Dorchal, biblioteca medieval, manuscritos, Valencia, predicación.

\begin{abstract}
This article analyses the library of Pere Dorchal, a priest at the Cathedral of Valencia (Spain), focusing on the post mortem inventory of his collection (1419). An analysis is conducted of its content, a paradigm of the preaching library, and his life is reconstructed.
\end{abstract}

Key Words: Pere Dorchal, Medieval Library, Manuscripts, Valencia, Preaching.

Sumario: 1. Biografía. 2. Testamento. 3. Biblioteca. 3.1. Descripción externa de los libros. 3.2. Descripción interna de los libros. 4. Conclusiones. 5. Bibliografía. 
El número de libros incluidos entre los bienes inventariados que aparecen en la documentación notarial de la ciudad de Valencia en la primera mitad del siglo XV no es muy abundante excepto los vinculados al ámbito eclesiástico ${ }^{1}$. Entre los posibles motivos que explicarían esta carencia estarían, en primer lugar, el elevado precio de los ejemplares que limitaba su adquisición por eso la mayoría de las veces el libro era más un producto de uso mercantil que de lectura en sí, por tanto, era habitual utilizarlo como elemento de cambio (compra-venta o empeño, penyora) para obtener un beneficio económico o como elemento de ostentación pues si nos atenemos a los títulos descritos suelen ser ajenos a la formación del propietario y, en segundo lugar, el propio acceso a la alfabetización, al menos al conocimiento de la lectura ya que la escritura solía limitarse a nobles dirigentes, a eclesiásticos o a burgueses con una actividad laboral concreta (comerciantes o notarios) ${ }^{2}$, pues muchos de los poseedores de libros son iletrados.

Al margen de todo ello, el libro es transmisor de la palabra, del saber, de ahí que fuera una preocupación constante de la municipalidad valenciana extender y facilitar el acceso a la lectura al mayor número posible de ciudadanos. En ese contexto se explica la compra de casas para instalar escuelas donde cualquiera que pudiera pagar su aprendizaje, pudiera asistir. Además los jurados de la ciudad de Valencia solían contratar eclesiásticos para que leyeran la Biblia, además de otros libros sagrados, a todos aquellos ciudadanos que quisieran conocerla y no pudiesen pagar el aprendizaje escolar. Una de las consecuencias de esa lectura pública en voz alta fue la recomendación de las altas instancias eclesiásticas que exhortaban a los estudiantes a clérigos a saber leer con voz apropiada para que los feligreses, en la medida de lo posible, pudieran aprovechar las lecturas realizadas al menos durante los oficios sagrados pero con especial hincapié en el sermón pues al ser en la propia lengua de la feligresía era la vía de adoctrinamiento ${ }^{3}$ por excelencia. La importancia del sermón como ruta propagandística traspasa el mero ámbito eclesiástico y se adentra en el político hasta el punto de que los propios jurados de la municipalidad de Valencia se encargarían de contratar, a costa del erario público, predicadores para el periodo cuaresmal ${ }^{4}$. Esos predicadores solían estar precedidos por su fama y esa fama se conseguía a través de una sólida formación eclesiástica, al menos entre el clero alto y urbano que había de plasmarse mediante la palabra de ahí la necesidad de la lectura y el estudio a través del libro aparte de que el ejercicio diario de la actividad sacerdotal les exigía la posesión de libros (misales, breviarios etc.). Todo ello contribuye a explicar por qué sus bibliotecas particulares son la excepción en el panorama librario valenciano para este periodo.

${ }^{1}$ SANCHIS Sivera, Estudis d'història cultural, pp. 79-94.

${ }^{2}$ Gimeno, La escritura en la diócesis de Segorbe [tesis doctoral inédita], I, p. 449.

${ }^{3}$ Aparte de los sermones, la catequesis es otra de las armas de adoctrinamiento utilizadas para llegar a la población. No implica aprendizaje de la lectura sin embargo se encuentra en los límites de la oralidad de carácter recitativo-memorístico, una forma de subyugación. La palabra seduce más que incita a la reflexión. FERrer Gimeno, La lectura en Valencia (1416-1474) [tesis doctoral inédita], ff. 71-74.

${ }^{4}$ Entre los predicadores contratados se incluirá el propio confesor del infante Juan de Aragón, hermano del rey Alfonso el Magnánimo. Archivo Municipal de Valencia (en adelante AMV). Lletres misives, 1418$1423, \mathrm{~g}^{3}-14$, ff. $98 \mathrm{v}-99 \mathrm{r}$. 
Un buen ejemplo de biblioteca eclesiástica excepcional para la primera mitad del siglo XV valenciano lo constituye la del sacerdote beneficiado de la catedral de Valencia Pere Dorchal, no solo por la cantidad sino también por la calidad de los títulos descritos. Según el inventario de sus bienes realizado por sus albaceas el 29 de abril de $1419^{5}$ poseía una biblioteca compuesta por treinta y cuatro volúmenes lo que ya de por sí nos indica que era una biblioteca excepcional comparada con otras bibliotecas contemporáneas suyas ${ }^{6}$. Sin embargo esa excepcionalidad no será sólo por su cantidad sino más bien por la calidad de los títulos descritos. Así, incluye autores poco frecuentes (por ejemplo Johannes Beleth) o títulos inéditos (La istòria del cavaller que entrà en lo purgatori de sent Patrici), pero además todos los títulos registrados se agrupan por temas de formación eclesiástica, devocional, penitencial o de carácter apocalíptico, temas reiterativos entre los predicadores de la época por los momentos convulsos vividos tanto en lo religioso (final de Cisma de Occidente) como en lo político (Interregno). Una biblioteca relevante construida sobre el interés cognitivo de su propietario aunque no sin dificultad pues su situación económica, a tenor de la documentación encontrada, no debía ser muy boyante lo que también explica que predomine el libro funcional, el papel como materia escritoria y encuadernado en pergamino sobre el códice.

Por último hay que señalar la circunstancia de que Pere Dorchal fue contemporáneo de san Vicent Ferrer, paradigma de predicador, que falleció también el 5 de abril de 1419 .

\section{BIOGRAFÍA}

Todos los registros documentales con alguna mención a Pere Dorchal están datados después de 1400 y relacionados con el hecho de ser beneficiado de la catedral de Valencia, a excepción de la documentación de carácter personal vinculada a su muerte: su testamento, 25 de abril de 1419, y el posterior inventario de bienes post mortem, 29 de abril del mismo año. Era hijo de Guillem Dorchal y Barthomeua. Su padre ya había fallecido en el momento de realizar el testamento Pere Dorchal pero no su madre que, a juzgar por sus disposiciones testamentarias, era anciana y estaba en malas condiciones físicas y psíquicas. Tuvo, al menos, un hermano o hermana pues sus sobrinos, hermanos entre sí, son mencionados en su testamento: Antoni Vidal, pelaire, Joan Vidal, mercader, Francesc Vidal, marinero, Angelina, sin especificar ningún detalle más excepto que tenía un hijo, Jaumet, que vivía en casa de Pere Dorchal. A cada uno de ellos les lega 50 sueldos. También figura Jacmeta, esposa de Martí Visedo de Massamagrell, que tenían una hija: Anthònia. Jacmeta debía ser también sobrina, a pesar de que no especifique los lazos consanguíneos en el testamento, pues le lega la misma cantidad, 50 sueldos, que al resto de los sobrinos, si bien podría darse el caso de que fuera hija de otro hermano o hermana diferente de los otros cuatro pues en caso de ser una sirvienta se solía especificar esa relación. De todos modos, conviene

${ }^{5}$ Archivo de la Catedral de Valencia (en adelante ACV). Protocolos 3678. Notari Lluís Ferrer, 29 abril 1419.

${ }^{6}$ SANCHIS Sivera, Estudis d'història cultural. 
tener en cuenta que muchas veces el no coincidir el mismo apellido entre hermanos era bastante habitual entre gente no noble, sobre todo entre las mujeres?

Sobre su actividad sacerdotal, siempre aparece vinculada a su beneficio catedralicio, aunque nunca se especifique qué beneficio era y, de momento, resulta imposible averiguarlo ya que, por sus mismas características, nadie es mencionado en los listados de beneficiados de la catedral de Valencia ${ }^{8}$. Así, el 15 de noviembre de 1402, junto a Raymundo Piquer, también sacerdote beneficiado de la catedral de Valencia, figuran como albaceas del sacerdote Guillem Puymeni. En el mencionado documento autorizan a Francesc Martorell, párroco de la iglesia de Puçol, para recibir en su nombre 15 florines de oro de Aragón y un breviario que había legado a la catedral de Valencia Guillem Puymeni9.

Luego el 27 de noviembre de 1402 recibe la cantidad de 15 florines de oro de Aragón de manos de Guillem Romaní, pelaire, ciudadano de Valencia, por diversos trabajos realizados a la muerte de Llorenç Beyani, sacerdote beneficiado de la catedral de Valencia, y del que Pere Dorchal era albacea junto con Bernat Romaní, notario, ciudadano de Valencia ${ }^{10}$.

También consta como albacea en el testamento de Arnau Moragues, sacerdote beneficiado de la catedral de Valencia, junto al sacerdote Domènech Pastor el 16 de marzo de $1403^{11}$.

Posteriormente figura en un documento datado el 24 de marzo de 1403 en Valencia sobre los trabajos pagados a diversos operarios por la construcción de una caja para guardar un breviario en pergamino, legado a la iglesia de Sant Esteve por Llorenç Veya. Pere Dorchal es uno de los albaceas junto con el notario Bernat Romeu ${ }^{12}$.

Después en 1405 figura como ejecutor testamentario del párroco de Albal, Francesc Sossies, pues había encomendado un retablo para la capilla de san Bernabé de esa iglesia parroquial al pintor Pere Nicolau ${ }^{13}$.

Por último, el 15 de octubre de 1415 su nombre está vinculado de nuevo como albacea testamentario de Domenech Bernat, pastor, lamentablemente es un documento inconcluso ${ }^{14}$ que impide dar más detalles que expliquen esa designación.

Respecto a su vida privada, Pere Dorchal habitaba una casa de la parroquia de Sant Pere de la ciudad de Valencia ${ }^{15}$, bajo el señorío del beneficio de sant Vicent mártir, en

\footnotetext{
7 Rivera Garretas, “Una vida en relación. Juana de Mendoza”, p. 108.

${ }^{8}$ En 1430 había un total de 195 beneficiados en la catedral. Pons Alós, y CÁrcel OrTí, "La diócesis de Valencia”, p. 94.

9 ACV. Protocolos 3656. Notari Jaume Monfort, 15 noviembre 1402.

10 ACV. Protocolos 3656. Notari Jaume Monfort, 27 noviembre 1402.

11 ACV. Protocolos 3671. Notari Luis Ferrer, 16 marzo 1403.

12 ACV. Protocolos 3671. Notari Luis Ferrer, 24 marzo 1403. Sanchis Sivera utilizó este documento al hablar de la forma de guardar los breviarios en las iglesias pero no mencionó a Pere Dorchal. SANCHIS SIVERA, Estudis d'història cultural, p. 69, nota 34.

13 Llanes i Domingo, L'obrador de Pere Nicolau, [tesis doctoral inédita], p. 173.

14 ACV. Protocolo 3665. Notario Joan Llopis, 15 octubre 1415.

${ }^{15}$ La zona de la iglesia de Sant Pere era una de las más solicitadas por su proximidad al centro político y espiritual de Valencia y con alquileres más altos. García MarsiLla, Vivir a crédito, p. 154.
} 
la misma calle donde se localizaba la casa de la cofradía de Sant Jaume ${ }^{16}$. Una casa que debía compartir con su madre y su sobrino, Jaumet, que tenía bajo su protección, quizás para darle una formación gramatical. La casa limitaba, pared medianera, por un lado, con una casa que también pertenecía al beneficio instituido de sant Vicent mártir por la catedral de Valencia, por el otro lado, con la casa de na Blanquita, hija del mercader en Montblanch y, por la parte trasera, con la de micer Guillem Çaera. Estas casas no debían ser muy grandes por el espacio descrito, unos $50 \mathrm{~m}^{2}$ : una casa de una sola planta con un vestíbulo que haría funciones de despacho; a continuación el comedor, un dormitorio, la cocina y un trastero encima de la cocina. Siguiendo el inventario parece ser que tanto su madre Barthomeua como su sobrino Jaumet dormían en el comedor pues hay descrita una cama equipada con colchón y ropa de cama, que tal vez ocuparía su madre al estar más delicada de salud, y un colchón sin más, que ocuparía su sobrino cada noche. Una casa sin ninguna suntuosidad a tenor de los calificativos más usados para describir los útiles: "squinçat, vell, de pocha valor". La casa pasó a ser ocupada por mosén Arnau Çapujada, a censo de 18 sueldos anuales pagados por la fiesta de san Joan Baptista, con luismo y fadiga, derecho entifitéutico y de realme según los fueros de Valencia ${ }^{17}$, tras la muerte de Pere Dorchal.

Entre sus enseres aparecen descritos varios objetos materiales relacionados con diversas actividades escriturarias lo que induce a pensar que debió de desarrollar tareas de carácter administrativo privado, como contabilidad tanto para la propia catedral, por estar entre sus libros un libro racional, como redacción de documentos para compensar económicamente el más que probable escaso beneficio catedralicio. De este modo, en la entrada de la casa ya aparece descrito "un studiet de fust, vell, en que havia alguns qüerns de paper. Item, una caxeta de fust ab la cuberta levada, vella, en que havia alguns papiracios[sic]". En el comedor, "una caxa de fust migancera, en que havia algunes cartes", "unes thesoretes[sic], "un arquibanch de fust, nou, ab dos caixons, en lo hu stà paper e l'altre és ple de scriptures velles". En el dormitorio, "una caxeta xicha ab algunes cartes", "un faristolet xich ab son peu", "una caxa de fust migancera plena de scriptures e paperots e librots, de pocha valor". En el trastero, "un banquet alt, de fust, cubert de drap, per scriure", quizás el sustituido por el nuevo. Todas estas tareas escriturarias quedan reforzadas con la descripción detallada de su biblioteca desarrollada en otro apartado.

En otro orden de cosas, Pere Dorchal pertenecía a la cofradía de Sant Narcís de la ciudad de Valencia, "loable confraria de Sent Narçís de la dita ciutat de la qual yo són cofrare" y a la que legó según disposición testamental 10 florines de oro comunes de Aragón. Esa cofradía, junto con la de Santa María y Sant Jaume, era una de las más importantes de Valencia. Su fundación obedeció a la numerosísima presencia de mercaderes oriundos de Girona en la ciudad de Valencia durante todo el siglo XIV y de cuya ciudad era patrón san Narcís. Hay discrepancias en torno a la fecha exacta de su fundación pues si bien en 1334 les fue concedido un privilegio para construir una capilla donde venerar al santo en la iglesia de Sant Joan del Mercat, no fue hasta 1356 cuando se fundó oficialmente la cofradía al serles legados 50 sueldos para ese

16 En la casa de la mencionada cofradía de Sant Jaume estuvo ubicada la Generalitat Valenciana desde 1404 hasta su localización definitiva en el palacio hoy conocido.

17 Para mayor información sobre dichas cargas véase GARCIA MARsilla, Vivir a crédito. 
menester según consta en el testamento de Guillem Amalrich ${ }^{18}$. Sin embargo, esta última fecha es cuestionada pues hay noticias de que en 1346 la iglesia de Sant Feliu de Girona, donde reposan los restos del santo mártir Narcís, pidió al obispo de Valencia "que permetés a un aplegador, que portava una capelleta de Sant Narcís, de postular per les obres del temple" en la ciudad de Valencia justificadas por la existencia de la cofradía y así terminar las obras en la mencionada iglesia gerundense en honor del santo $^{19}$. Esta petición confirmaría que la cofradía de Sant Narcís además de su gran importancia estaba ya consolidada en esa fecha de 1346 en la ciudad de Valencia. Desgraciadamente en la iglesia de Sant Joan del Mercat de Valencia hubo un incendio en 1371 que destruyó la capilla del santo aunque fue reconstruida en 1384 por un privilegio del rey Pedro IV de Aragón.

La cofradía de Sant Narcís fue la primera que tuvo sede propia con literas para dar descanso y atención a los cofrades pobres y enfermos. Su organigrama lo constituían cuatro mayorales como dirigentes, a continuación los andadores o missatgers, encargados de convocar a los cofrades para acompañar al cofrade difunto a la sepultura, el resto lo conformaban los cofrades en general. La cofradía podía estar constituida por un número máximo de cien hombres y ciento cincuenta mujeres, con una cota anual de 6 sueldos, la más cara de toda la ciudad durante el siglo XIV. Este hecho descoloca un poco a Pere Dorchal pues económicamente no debía estar muy boyante ya que en su inventario, sólo aparecen descritos "entre reals e dos menuts, nou lliures e quinze sous e una quartvetla de florí", además de "VIII culleretes d'argent". Quizás lo compensaba con el ejercicio del oficio patronal del santo puesto que figura entre sus libros: "un libre en pergamí, cubert de posts verdes, de l'ofici de sent Narcís".

Además, los cofrades estaban obligados al menjar o comida de hermandad anual y a la pietança o caridad con los pobres. Una de las prácticas más extendidas entre los cofrades, no solo de Sant Narcís sino también de las demás cofradías, era atender a pobres vergonyants o pobres vergonzantes. Una práctica que Pere Dorchal recogía entre sus disposiciones testamentarias al consignar parte de la venta de sus bienes para "persones indigents e havents neçessitat[sic] de la mia parentela, axí de part de mare com de pare".

Otro de los privilegios de esta cofradía, compartido con las de Sant Jaume y Santa María, era tocar campanadas a muerto desde la catedral así como una esquila que avisase del paso del cortejo fúnebre ${ }^{20}$. Privilegios que produjeron más de un litigio entre los cofrades de las tres cofradías por ocupar lugares preferentes en los actos religiosos celebrados en la ciudad u ostentar la insignia real en dichos actos ${ }^{21}$ así como su colocación procesional a la derecha o izquierda de la misma ${ }^{22}$. Sin embargo, Dorchal renunciaría expresamente a todos esos fastos en su funeral, "ne vull que en la dita mia sepultura entrevinga o sia la proçessó general de la dita seu", por amor a su madre

18 Orellana, Valencia antigua y moderna, II, p. 339.

19 MArquès, "El temple de Sant Feliu de Girona, al s.XIV”, p. 134.

${ }^{20}$ Véase: ACV. Pergamino 8403, 15 julio 1371. ACV. Pergamino 5236, 24 octubre 1378.

21 Roca Traver, "Interpretación de la cofradía valenciana”, p. 62, nota 70.

22 Carta de los jurados de Valencia al rey Joan I, con fecha de 22 de julio de 1393. Rubio Vela (ed.): Epistolari de la València medieval, I, pp. 327-329. 
pues, "car mes facultats temporals són flaques e seria tolre la vida a ma mare, la qual és molt vella e posada en nececitat[sic]".

Otra noticia que refuerza la importancia de la cofradía de Sant Narcís en Valencia descansa en la misiva del 19 de mayo de 1394 que mandaron los jurats de la ciudad de Valencia a los jurats de la ciudad Girona solicitándoles una reliquia del santo pues "hajam affecció desijable al creximent de les dites devoció e confraria, vostra honorable saviesa e bona amistat"; una cofradía que en Valencia la componen "cert nombre de notables ciutadans nostres axí clergues com lechs, hòmens e dones"23. Indudablemente detrás de este interés piadoso se esconde un afán recaudatorio municipal en relación al posible aumento de cofrades.

Y por último, otro detalle que demuestra la importancia de la cofradía de Sant Narcís fue la elección de su sede como lugar de reunión de los tres estamentos del Reino de Valencia el 28 de junio de 1412 después de la elección de Fernando I de Trastámara como nuevo rey de la Corona de Aragón ${ }^{24}$.

Por lo tanto, esta vinculación a la cofradía de Sant Narcís significa un origen burgués mercantil de Pere Dorchal por parte paterna, aunque nunca fuera especificado el oficio del padre en su testamento ni tampoco su nombre fuera incluido entre los cofrades de más raigambre de la cofradía. El sacerdote sólo se refiere a su padre en su testamento para señalar que estaba enterrado en el cementerio de la iglesia parroquial de Sant Esteve de Valencia, es decir, donde solían ser enterradas las personas con escasos recursos económicos y dónde él y su madre deberían ser enterrados también, "fossa que ma mare e yo havem aquí e y jau mon pare". No obstante, entre sus sobrinos aparece uno, como mercader, Joan Vidal, quizás el continuador de la estirpe en el oficio, pues los otros son artesanos o marineros, aunque hay un detalle que refuerza el carácter burgués familiar como la descripción detallada, entre sus pertenencias, de dinero correspondiente a "certes quantitats... pertanyents e donades per certes fadrines a maridar e com faràn matrimonis". La cofradía de "les òrfenes a maridar" era sólo para burgueses y excluía a nobles y clérigos; si Dorchal era la excepción sería por su ascendencia familiar y sus posibles vinculaciones del mismo tipo con alguna de las designada a maridar ${ }^{25}$. Por tanto, en el inventario de bienes realizado por sus albaceas el 29 de abril de $1419^{26}$ en la casa que habitó y donde murió encontraron, dentro de un saquito de cáñamo:

en lo qual havia una cèdula per la qual par que lo deffunct tenia per a certes orfenes a maridar, quantitats pujant és a suma de CCCL sous, ço és: per a Johana, filla d'en Steve Corça: L sous; per a Dolça, filla d'en Vicent Just: L sous; item, per a Anthònia, filla d'en Martí Vijado de Macamagrell: C sous; item, per a Constanca, filla d'en Pere

${ }^{23}$ Ibidem, I, pp. 225-226.

${ }^{24}$ Gimeno Blay, El Compromiso de Caspe (1412), pp. 453-455.

${ }_{25}$ Aunque excede el fin de este estudio baste recordar que la orfandad se consideraba paradigma de pobreza y posibilidad de marginalidad, para remediarlo en el siglo XIV un grupo de ciudadanos crearon en Valencia la "loable almoina de les òrfenes a maridar". "Cofradía de carácter laico y privado, expresión del sentimiento caritativo -no exento de un cierto afán de prestigio social-de los mercaderes y burgueses que la crearon y que, generación tras generación la mantuvieron con su propio esfuerzo a lo largo de las centurias medievales". Rubio Vela, "Infancia y marginación", p. 126.

${ }^{26}$ ACV. Protocolos 3678. Notario Lluís Ferrer, 29 abril 1419. 
Aguilar: L sous; item, per a la neboda d'en Gali: L sous; item, per a la dita Dolça: C sous.

E en lo dit sach són trobades realment CLXXXXV sous, VIII diners. Es trobat scrit en lo dos de la dita cèdula que dels dits diners havia prestats a son compte: n'Illari, notari: XXII sous, item, a'n Francesch Vidal: XXII sous; item, que près lo defunct: CX sous.

Sobre los nombres de esas huérfanas destaca el de Anthònia, hija de Martí Visedo de Massamagrell, suponemos que hija de Jacmeta, esposa del anterior, una de las destinatarias del testamento de Pere Dorchal, con 50 sueldos por una vinculación de parentesco, posible sobrina, o afectiva, criada a su servicio.

\section{TESTAMENTO}

$\mathrm{Su}$ testamento sigue las pautas típicas del periodo. Es un testamento nuncupativo con una base escrita, "apellats los notari e testimonis deiús scrits", es decir, el notario Lluís Ferrer y los albaceas Guillem Castelló, sacerdote beneficiado de la catedral, y Antoni Vidal, pelaire, sobrino de Dorchal, según consta en el mismo "derrera volentat o per dret de codiçils o de nuncopatiu[sic]". Si bien nunca se indica que enfermedad pudo padecer para estar cerca de una muerte ineludible, "jatsia malalt de cors, de tal malaltia de la qual tem morir", no se puede descartar algún conato de peste aunque no sería hasta 1420 cuando se declarara un brote epidémico en la ciudad. El testamento prosigue con las disposiciones legatarias a sus familiares, a sus sobrinos, 50 sueldos, así como otros 50 sueldos a sus albaceas Guillem Castelló, sacerdote beneficiado de la catedral de Valencia y a su sobrino Antoni Vidal, pelaire, a su amigo personal el sacerdote Joan Lillet ${ }^{27} 25$ sueldos. Pero más allá de las mandas habituales, "leix al molt reverent senyor bisbe de València, dèu sous" ${ }^{28}$, todo el testamento gira en torno a suplir cualquier desamparo en que pueda quedar su madre Bartomeua y disponer su manutención pues su estado de salud física y psíquica debía estar bastante deteriorado. La dejó bajo el cuidado de su sobrino Antoni Vidal:

axí que la dita mare mia, la qual es molt vella e per si no poria estar o regir-se, stigua en poder del dit n'Anthoni Vidal, marmessor e nebot meu, lo qual yo prech que la tengua e aquella e los dits béns e drets meus tengua, administre e regescha e alimente, proveescha e faça tots sos obs a la dita mare mia... de la renda e fruyts que de aquells exiràn de tota la vida de aquella ${ }^{29}$.

Por ese motivo estableció una cláusula en que dejaba en suspenso todo lo anterior en favor de su madre, "les persones dessús nomenades no sien pagades ne los dits

${ }^{27}$ La única noticia documental que tenemos por el momento corresponde al 20 de julio de 1451 en que Joan Lillet permutó su beneficio en la catedral de Valencia, bajo la advocación de sant Jaume, a Bernat Blasco. Munsuri, Perspectiva socio-económica del clero secular en la Valencia del siglo XV, [Tesis doctoral inédita], II, p. 1447.

${ }^{28}$ El obispo era Hug de Lupià (1398-1427).

29 ACV. Pergamino 6716, 25 abril 1419. 
meus marmessors puxen ésser destrets a pagar aquelles fins après mort de la mare mia deiús scrita". Todo ello refuerza la idea de la escasez de medios económicos de Pere Dorchal y su temor a la posible indigencia de su madre si prolongaba su vida. A pesar de todo Pere Dorchal representa la mentalidad crediticia de la Valencia del momento al incluir otra cláusula testamentaria en que, una vez muerta su madre, todos sus bienes y derechos deberían ser divididos en dos partes: una parte,

sien comprats censals perpetuals en lochs e segurs e ab amortizació e licençia[sic] del senyor rey sien assignats a la dita esgleya[sic] parrochial de sent Stheve e als rector e benefficiats de aquella...dels quals censals o pensió annual de aquells en via de caritat... tants anniversaris cascún any e perpetualment a quants basten per ànimes de la dita mare mia e de mi e de tots feels deffuncts.

El Purgatorio era el espacio de vinculación entre el presente y el más allá, el lugar generador de actividad económica ${ }^{30}$. Por eso este apartado es la demostración palpable de la vinculación memorial entre los vivos y los muertos y que el heredero, en este caso el sobrino, debería cumplir "orden e faç a mi hereua universal, per dret de instituçió, la mia ànima". Una preocupación por el Purgatorio que, al mismo tiempo, se refleja en su biblioteca y que proyectaría a través de sus prédicas y en las disposiciones de las misas de difuntos y aniversarios además de validar como entran en la economía cotidiana ese mundo intermedio del más allá. La otra mitad de la potencial venta sería distribuida por ambos albaceas entre "persones indigents e havent neçessitat[sic] de la mia parentela axí de part de mare com de pare". Una insistencia de nuevo entre pobres vergonyants tan habitual en la Valencia bajomedieval por culpa de la desmesura en vivir a crédito ${ }^{31}$, cuya consecuencia inmediata podía llevar a la pérdida de todos los bienes. Una práctica mercantil enmascarada de carácter piadoso habitual entre los cofrades, en general, y, en particular, entre las principales cofradías como la de Sant Narcís. Sin olvidar la práctica crediticia directa también practicada por Pere Dorchal, "havia prestats a son compte", con el dinero destinado a òrfenes a maridar, ya detallado previamente.

Desgraciadamente faltan los registros documentales sobre el cumplimiento de todas estas disposiciones, incluida la venta de sus bienes "als més de preu donants", pero con la particularidad de que no fuera en pública subasta, "omesa subastació e tota altra solemnitat necessaria o acostumada". Tal vez, esa insistencia se deba, no solo a su preocupación por no alterar en demasía a su madre, con su muerte sino también una forma de evadir a la municipalidad el dinero obtenido por la venta de los bienes por la parte correspondiente de la subasta.

\section{BIBLIOTECA}

Las bibliotecas durante el primer tercio del siglo XV, en la ciudad de Valencia, no contienen muchos volúmenes a excepción de las eclesiásticas y la de Pere Dorchal

30 Aventin Puig, "Mercat de rendes, mercat de salvació", p. 135.

31 García Marsilla, Vivir a crédito. 
es un buen ejemplo de ello. La primera referencia que tuvimos de esta biblioteca fue la mencionada por Josep Sanchis Sivera ${ }^{32}$ en su Bibliología valenciana medieval donde figura: "Inventari de Pere Darchel, prevere.- 29 d'abril de 1419. Decret, pergamí.- Sermons, pergamí.- Exposició de brapch, pergamí". Consultadas las fuentes nos encontramos con una biblioteca de treinta y cuatro volúmenes descritos con bastante detalle y que, en una primera lectura ya demuestran que es la biblioteca de un predicador. No comprendemos qué pudo llevar a Sanchis Sivera a ignorarla e incluso a transcribir el apellido Dorchal por Darchel, ya que aparece el mencionado personaje en diferentes documentos, incluidos en este estudio, y que el ilustre canónigo debió de conocer. Tampoco sabemos cómo transcribió "Exposició de brapch", pues tampoco consta en ninguno de los registros del inventario, tal vez, lo incluyese en el mismo por error y perteneciera a otro documento objeto de su estudio. Sin embargo, lo que más nos ha sorprendido es que hubiera ignorado el registro del primer asiento del inventario de libros que a continuación detallamos.

Los libros se hallaban en una caja de madera en la habitación donde dormía Pere Dorchal: "Item, una caxa de fust streta e larga en la qual havia los libres següents":

[1]Primerament, tres qüerns, en paper, ligats, parque stà: La istòria del cavaller que entrà en lo purgatori de sent Patrici ${ }^{33}$ e altres coses.

Esta obra es la primera vez que la encontramos inventariada en Valencia formando parte de los títulos que componen una biblioteca. A pesar de gozar de cierta popularidad literaria los viajes a ultratumba ${ }^{34}$ y sobre todo al Purgatorio de San Patricio, situado en Station Island, Lough Derg, condado de Donegal (Irlanda), no fue una obra muy conocida más allá del ámbito pirenaico y sus aledaños. Por tanto, uno, a pesar de la ambigüedad del título debe de ser la obra del caballero y escritor Ramón de Perellós (+ ca. 1424), quien realizó el viaje descrito en su obra publicada en 1398 en la que aparece el difunto rey Joan I de Aragón (1350-1396) que está purgando sus pecados, al igual que lo haría el mismo rey en la obra de Bernat Metge, Lo somni (1398-1399), todos contemporáneos de Pere Dorchal; dos, pudieron influir las posibles relaciones de ascendencia de Dorchal con la ciudad de Girona, como ya se ha explicado más arriba; tres, el hecho de que sea el primer libro descrito en el inventario hace pensar que lo estaba leyendo o había leído recientemente; cuatro, el hecho de que el registro incluya "e altres coses" nos lleva a preguntarnos si no contendría otros relatos del purgatorio o de ultratumba incluida la propia obra de Metge. De todos modos, hasta la fecha, las únicas referencias donde aparece citada la obra de Perellós en inventarios corresponden a la ciudad de Barcelona. Es el caso del inventario de 19 de abril de 1419 de Valença, viuda de Jaume Cirer, cofrero, que era el único libro que

32 SANChis Sivera, Estudis d'història cultural, p. 94.

33 Viatge al purgatori de sant Patrici, de Ramón de Perellós.

${ }^{34}$ Con el nacimiento del Purgatorio en el siglo XIII (véase LE GoFF, El nacimiento del Purgatorio) surge toda una literatura cuyo objetivo es purgar los pecados para llegar al cielo, por ello es mejor la intermediación de los santos. La imagen de san Patricio, santo irlandés del siglo V, será utilizada de forma literaria. La bibliografía al respecto es extensa, por eso remitimos a los estudios de RIQUER, Història de la literatura catalana, II, pp. 489-513 y MiQuel i Planas, Llegendes de l'altra vida, por haber tratado con detalle el tema. 
poseía ${ }^{35}$, y el de Gabriel Plaença, servidor de la Casa Real y ciudadano de Barcelona, realizado a su muerte el 10 de febrero de $1430^{36}$. En consecuencia, podemos compartir los comentarios de Stefano Maria Cingolani ${ }^{37}$ a propósito de las obras esgrimidas sobre la figura del rey Joan I:

Quin sentit té que el gest tranquil·litzador, de veure'l al purgatori i fer-lo públic, s'esdevingui més de tres anys després de la mort [Joan I]? I quin sentit té que es faci per mitjà de dues obres literàries, Lo somni i el Viatge al purgatori de Ramon de Perellós l'àmplia circulació de les quals no era assegurada i que, a més a més, eren obra de dos dels processats i, per tant, fonts "sospitoses", encara més si Metge és un epicuri i una esmunyedissa anguila?

Y por último, si lo comparamos con otros territorios de la Corona de Aragón por las afinidades lingüísticas, en los inventarios de Mallorca ${ }^{38}$ para este periodo encontramos que:

No copies of either Cobles or of a Dança de la Mort are recorded in Majorca, though they certainly circulated in Catalonia. Nor does the celebrated Viatge al Purgatori de sant Patrici by Ramon de Perellós appear in our lists.

Por todo ello podemos concluir la excepcionalidad de esta obra y la posibilidad de que la copiase el propio Dorchal, aunque no se indique en el inventario. Su interés radicaría en actualizar sus prédicas como resorte propagandístico en personajes y situaciones políticas convulsas que él mismo vivió (Cisma e Interregno).

[2]Item, un libre scrit en paper de Xàtiva, vell, ab cubertes de pergamí apellat: Miraculorum luce Marie $^{39}$ et exposicione apocalipsis ${ }^{40}$.

${ }^{35}$ Item, $\cdot I \cdot$ libret ab posts vermelles, en la primera pàgina del qual ha escrit en letra vermella qui comença: "Comença lo libre appellat: Purgatori de sant Patrici". E fina en la derrera pàgina: "Vita Beate Justine, Virginis". Madurell i Marimon, Manuscrits en català anteriors a la impremta, p. 41. No obstante, y considerando el final del libro, quizás fuese una parte de la Leyenda dorada de Vorágine donde también está incluida la vida de san Patricio.

${ }^{36}$ Item, un libre de paper, sotil, de sent Patrissi. IgLeSIAS I FONSECA, Llibre i lectors a la documentació notarial (1396-1475), [Tesis doctoral inédita], II, Apéndice documental, doc. 121.

${ }^{37}$ Metge, Lo somni, p. 265.

${ }^{38}$ Hillgarth, Readers and Books in Majorca 1229-1550, I, p. 172.

${ }^{39}$ No localizado. En el inventario de la catedral de Sigüenza de principios del siglo XIV en el asiento [60] aparece: Liber de miraculis beate Marie. RiUs SERRA, "Inventario de manuscritos de la catedral de Sigüenza", p. 435. También entre los inventarios descritos de los papas de Aviñón [93] Item, liber miraculorum beate Virginis, qui incipit: “Ad omnipotentis Dei laudem", et sermones vulgares, in uno volumine. Faucon, La librairie des papes d'Avignon, (en adelante MF), II, p. 6.

${ }^{40}$ Expositio in Apochalypsim (Catàleg dels ms. Bca. de Catalunya-103). 
[3]Item, un libre scrit en paper toschà, de mà del defunt, cubertes de pergamí comenca al libre de sent Alifonso $[\text { sic }]^{41}$ de laude virginis ${ }^{42}$ e han altres coses moltes.

[4]Item, un libre de paper, de sermons ${ }^{43}$, scrit de mà del defunt, cubertes de pergamí.

[5]Item, un libre en paper ab cubertes blaves intitulat: Constitutiones sinodales ecclesie Valencie ${ }^{44}$.

[6]Item, un libre en paper ab cubertes blanques intitulat: Johannes Bellot ${ }^{45}$.

[7]Item, un libre en paper cubertes vermelles intitulat: Magna partes libri racionalis ${ }^{46}$.

[8]Item, un libre en pergamí, cubertes de posts verdes en que són registrats los privilegis de la ciutat ${ }^{47}$.

[9]Item, un libre en paper, cubertes verdes, apellat: Dialogorum beati Gregorii ${ }^{48}$.

[10]Item, un petit libret en pergami, cubertes blaves, intitulat: De virtutibus antiquorum $^{49}$ e De ymagine mundi ${ }^{50}$.

[11]Item, un libre en paper ab cubertes vermelles, intitulat: Liber reponcitorum super tractatum misse.

[12]Item, un libre en paper, cubertes vermelles, apellat: Liber Ymnorum.

[13]Item, altre libre en paper ab cubertes vermelles, intitulat: Breviloquium Tarentacii super IIII $^{\circ}$ Libris summiarum ${ }^{51}$.

${ }^{41}$ El libro citado recoge distintos escritos copiados por el propio propietario, desgraciadamente no han sido descritos más allá de referirse al "libre de sant Alifonso", un título de difícil identificación aunque hay un libro de piedad de título parecido entre los solicitados por el rey Alfonso el Magnánimo, "L'offici de sant Alifonso". Hinojosa Montalvo, "Aportaciones a la bibliología", p. 215.

${ }^{42}$ Servasanto, Mariale de laudibus beatae Virginis Mariae, Olmos Canalda, Catálogo descriptivo de los códices de la Catedral de Valencia, 1943 (en adelante OC-209). También en MF, Item, Albertus de laudibus virginis Marie, copertus de viridi, II, p. 38.

${ }^{43}$ Los registros 4, 16 y 28 al tener un nombre genérico como sermons puede englobar sermones de autores conocidos copiados por el propio Pere Dorchal o sermones propios por eso resulta difícil su identificación.

${ }^{44}$ Andrés de Albalat, Jazperto de Botonach y otros prelados, Constitutiones synodales ecclesie Valentinae (OC-98). También en Item, Constitutiones Sinodales Valentie en paper e pregamí, cubertes de aluda blenches, biblioteca de Berenguer Scampa, canónigo de la catedral de Valencia, 31 julio 1409. MANDINGORRA, Leer en la Valencia del Trescientos [tesis doctoral inédita], II, Apéndice documental, doc. 139.

${ }^{45}$ En el inventario del obispo de Mallorca, Antoni de Collell, 13 noviembre 1349-3 marzo 1363 consta: Librum Johanis Belet qui incipit... angeliste. Posiblemente se refiere a él. También en MF, II, p. 41 Item, Johannes Beleth, De ecclesiasticis officiis, copertus de rubeo. También en Item, I libre scrit en pergamins, a la forma prop dita, ab cubertes de posts nues, ab I tenchador appellat Summa Iohannis Baylet, IGLESIAS I FonSECA, , Llibre i lectors a la documentació, doc. 246. Jean Beleth, teólogo francés. Sus años de florecimiento fueron entre 1135 y 1182. Su manual de litúrgia más famoso fue Summa de ecclesiasticis officiis (1162). Fue impreso con el título de Rationale Divinorum Officiorum.

${ }^{46}$ Libro donde se anotan las porciones correspondientes a cada canónigo en la mesa del capítulo.

${ }^{47}$ En el inventario de Juan Fernández de Porto, bachiller en derecho canónico y civil, aparece, Item un altre libre en paper scrit, appellat Privilegis e ab diverses repotacions, ab les cubertes engrutades verts, MANDINGORRA, Leer en la Valencia del Trescientos, doc. 65 (34). Furs i privilegis (OC-146-B).

${ }^{48}$ Gregorio I, papa, 540-604, Dialogorum Liber (OC-285). Item, liber dialogorum Gregorii (MF, I, p. 107 [156]). Item, liber dialogorum sancti Gregorii (MF, II, p. 10, [244]).

49 Joan de Gales, Breviloquium de virtutibus antiquorum. Catálogo de manuscritos de la Biblioteca Universitaria de Salamanca, ms. 1938, II, p. 269.

${ }^{50}$ Tal vez sea De imago mundi, Pierre d'Ailly $(+1420)$.

${ }^{51}$ Petrus de Tarantasia, luego Inocencio V, papa, Liber IV Sententiarum (OC - 109). Los comentarios al Libro de las Sentencias de Pedro Lombardo es el libro más conocido de este autor. 
[14]Item, un libret xich en paper ab cubertes blaves, intitulat: Stimulus amoris ${ }^{52}$. [15]Item, altre libre en paper, ab cubertes verdes, intitulat: Liber compoti et Algracis$m i^{53}$.

[16]Item, altre libre en paper ab cubertes verdes, és de sermons.

[17]Item, un libret, en paper, xich, cubertes verdes intitulat: Concordançes dels $X$ manaments ${ }^{54}$.

[18]Item, un libre en pergamí, xich, ab cubertes de post ab aluda blanca intitulat: Summa de penitencia de magistro Raymundo dita ${ }^{55}$.

[19]Item, un libret en pergamí ab cubertes de pergamí engrutades intitulat: Super correnta[sic] in missa.

[20]Item, un libre en pergamí cubertes de fust ab aluda blancha intitulat: Magister Summiarum $^{56}$.

[21]Item, una biblieta $^{57}$ en pergami, molt spessa, ab cubertes de fust ab aluda vermella. [22]Item, [sic] manipulus curatorum $^{58}$ en pergamí ab cubertes de fust ab aluda blancha.

[23]Item, un breviari de consueta de València, scrit en pergamí ab cubertes de fust ab aluda blancha.

[24]Item, unes horetes en pergamí ab set psalms ${ }^{59}$ e altres coses.

[25]Item, un libre en pergamí, cubert de posts verdes, de l'ofici de sent Narcís.

[26]Item, [sic] Soliloquium Augustini ${ }^{60}$, en paper ab cubertes vermelles.

[27]Item, un libret en paper ab cubertes vermelles, intitulat: De auctoritatibus virtutum et viciorum ${ }^{61}$.

${ }^{52}$ Iacobus Milanensis, Stimulus amoris Christi. Libro muy popular a principios del siglo XIV para el ejercicio de la devoción privada, en particular durante la misa. (Saenger, Books of Hours, pp. 264-265). También puede ser Pseudo-Buenaventura: Stimulus amoris (Bibliography of Old Catalogue Texts-1273).

53 Puede ser Gracisme o Graecismus de Evérard de Béthume, uno de los componentes del Doctrinal, tratado de gramática. Puede ser una mala transcripción de Liber Contemptus Mundi, disertación moral en versos rimados. Ambos títulos relacionados con el aprendizaje de la gramática.

${ }^{54}$ En los inventarios siempre aparece Els X manaments, con propietarios eclesiásticos o seglares, sirva de ejemplo: inventario del sacerdote beneficiado de la catedral de Valencia, Berenguer Tolosa, 3 junio 1362. Item, un libre de pregamí, tractat (...) deu Manaments, ab cubertes verts, MANDINGORRA, Leer en la Valencia del Trescientos, doc. 40 (20). Inventario del mercader Guillem de Cavanyelles, Barcelona, 7 diciembre 1423, Item, altre libre en forma menor, scrits en pergamins, appellat: Los X manaments, IGLESIAS I FonsECA, , Llibre i lectors a la documentació, doc. 93 (14). Por tanto, el añadido de Concordançes al título habitual sería una contribución del propio copista para afianzar el título.

55 Item, summa Raymundi de penitencia... (MF, I, p. 164, [814]). Raimundo de Peñafort, Santo: Summa de paenitentia.

56 Item, liber summarum magistri Petri Lombardi, copertus corio livido..., (MF, I, p. 241, [1844]).

57 Debe hacer referencia al tamaño de la misma al designarla en diminutivo. Era de uso corriente entre predicadores y ordenes mendicantes.

${ }^{58}$ Guido de Monte Rocherii, Manipulus curatorum, Inventario general ms. Biblioteca Nacional-4035.

59 Inocencio III, papa: Exposició dels set salms penitencials (Bibliography of Old Catalan Texts-819).

${ }^{60}$ Agustin, santo, Soliloquiorum libri duo (Inventario General ms. B. Nacional-203-I). Item, liber soliloquiorum Augustini, (MF II, p. 76, [322]). En ese inventario está ubicado entre los libros de sermones de san Agustín sobre libros de la Biblia y la Virgen María.

${ }^{61}$ Puede ser, Joan de Gales, Summa de vitiis et virtutibus. Texto muy apreciado para sermones con la inclusión de comentarios de los evangelios, la patrística y fuentes canónicas. Briscoe, Artes praedicandi, p. 37. 
[28]Item, un libret xich de sermons, en paper ab cubertes vermelles.

[29]Item, un libret en paper ab cubertes de pergamí, és de oficis e comenca: "In consacracione altaris".

[30]Item, altre libret en paper ab cubertes de pergamí en que son les misses que $\bullet$ deuen dir en temps de mortalitat ${ }^{62}$.

[31]Item, un libret en paper ab cubertes de pergamí que tracta de penitència ${ }^{63}$.

[32]Item, un libre en paper ab cubertes de fust vermelles apellat: Natura angelica, de maestre[sic] Francesch Eximenez ${ }^{64}$.

[33]Item, [sic] decretals ${ }^{65}$, en pergamí, velles ab cubertes de fust.

[34]Item, alguns librets e qüerns en paper, de pocha valor, ligats ensemps en dos volums.

\subsection{DESCRIPCIÓN EXTERNA DE LOS LIBROS}

Estudiar las características externas de los manuscritos es importante porque ayuda a conocer la posible situación económica de su propietario y las vías de adquisición de los ejemplares ante la dificultad de producción de los mismos y su encarecimiento.

\subsubsection{MATERIA ESCRITORIA}

Predomina el papel como materia escritoria, 65\% del total, porque era un material más barato y asequible para personas con ingresos limitados frente al pergamino que encarecía muchísimo el libro. A lo largo de todo el inventario, el papel como materia escritoria aparece no sólo en la descripción de los libros personales, sino también en diferentes lugares de la casa, como por ejemplo en la entrada, donde había un escritorio, "un studiet de fust vell, en que havia alguns qüerns de paper" y una caja en que "havia algunes papiracios[sic]". Quizás se justifique su presencia porque llevase algún tipo de contabilidad y era la materia más apropiada para ese tipo de actividades. En el comedor de la casa también aparece descrito un arquibanco con dos cajones "en lo hu stà paper e l'altre és ple de scriptures velles". Y, aunque el título genérico es papel, scrit en paper, hay dos registros donde se detiene a describir la calidad de ese papel. Es el caso del registro [2] "un libre, scrit en paper de Xàtiva, vell". Si lo identificó el notario que realizó el inventario fue por la filigrana del papel, era el escudo de la ciudad de Xàtiva, el grosor, el tamaño más largo de las hojas, la deficiente trituración de las fibras, el verjurado irregular, el encolado de almidón y un fuerte satinado. El título corresponde a una obra religiosa por lo que cabe pensar si no sería una obra adquirida por Pere Dorchal en alguna almoneda o lo tenía en préstamo, ya que al ser

${ }^{62}$ Misal Valentino. En fol. 501 contiene De la misa de san Roque en tiempo de peste (OC-60).

${ }^{63}$ El título genérico no permite identificarlo con ninguno de los tratados más conocidos como el de Thomas de Salisbury. Item, Summa de penitencia, Thome Salherensis (MF, I, p. 121, [312]).

${ }^{64}$ Libro moralizante donde se exponen los peligros que nos amenazan si nos apartamos de Dios. Los ángeles revelan los secretos divinos (Dominguez BordonA, p. 73). El título original es Llibre dels àngels (1392) pero es habitual simultanear el título en catalán y en latín aunque el contenido sólo exista en catalán.

65 Inocentius IV. Decretales. “... Innocentio papa quarto super decretalibus tam veteribus quan ab eodem..." (OC-37). 
descrito entre los primeros podía significar que lo consultaba con frecuencia como fuente para sus sermones, como son los temas recurrentes sobre la Virgen María y el apocalipsis. El siguiente libro [3] se describe como "libre scrit en paper toschà, de mà del defunt". Era un tipo de papel propio de la zona toscana, de gran calidad, que llegaba a Valencia por importación aunque pronto fue elaborado en esta ciudad por trasladarse diversos proveedores a la misma ${ }^{66}$. Tal vez, lo más interesante sea "e han altres coses moltes", porque podrían incluir tanto títulos populares del momento como una posible producción propia de Pere Dorchal. Por desgracia, esa falta de interés en el momento de la elaboración del inventario limita el conocimiento de las tendencias literarias y un acercamiento fidedigno a las lecturas practicadas en el periodo.

Respecto a los ejemplares descritos sobre materia escritoria en pergamino, $32{ }^{\prime} 35 \%$, el inventario nunca especifica la calidad del mismo y, por el tipo de títulos a los que se halla asociado, quizás fueron prestados por alguna institución u otro particular o adquiridos por Pere Dorchal en alguna almoneda en un momento económico personal boyante.

\subsubsection{INSTRUMENTOS ESCRITORIOS}

El inventario no hace ninguna referencia a los instrumentos escritorios utilizados para copiar los textos y que, sin duda, deberían existir en la casa. Serían pluma o cálamo al igual que tintero y tinta, que tampoco aparecen recogidos en el inventario. Cabe la posibilidad de que no fuesen de excesiva calidad y por ello de escaso interés para hacerlos constar, lo que contradice el espíritu del propio inventario de detallar todos los objetos encontrados en la casa. Sólo consta: "Item, dos ganivets xichs, en una bahina negra", instrumentos de uso para escribir pues se raspaba la tinta de lo equivocado sobre el texto.

\subsubsection{FORMA, TAMAÑO Y COMPOSICIÓN}

Todos los ejemplares reciben el nombre de libre, es decir, disposición rectangular con tapas y hojas del mismo tamaño, sin embargo cuando son de pequeño tamaño se especifica con el adjetivo petit, xich o libret, $32^{\prime} 35 \%$. Otros se agrupan bajo títulos en diminutivo, biblieta y horetes. Sobre la composición de los libros nada se detalla más allá del termino qüerns para hablar de aquellos que no tienen importancia según el inventario como el último registro "alguns librets e qüerns... ligats ensemps en dos volums", o el primer título descrito de la biblioteca, "tres qüerns en paper, ligats", lo que puede reforzar la idea de ser una copia del propio Dorchal.

\subsubsection{ENCUADERNACIÓN}

Bajo el término ligat se entiende que era una obra donde todos los cuadernos están unidos, encuadernados, pero ningún ejemplar descrito sobresale por la riqueza de su encuadernación. Casi todos están encuadernados en pergamino, pergamí, o en made-

\footnotetext{
${ }^{66}$ Hinojosa Montalvo, "Aportaciones a la bibliología", pp. 224-225. Entre los proveedores se incluye a "Francesch Barceló, de Valencia (1419)".
} 
ra, post o fust, unas veces esta materia sin revestimiento u otras especifica el tipo de cuero que lo cubre, "aluda blancha", "aluda vermella", o "pergamí engrutat"67 o sólo su color: "blaves, blanques, vermelles, verdes".

\subsubsection{LENGUA}

Identificar la lengua en la que ha sido escrito un libro a partir de la descripción aportada por el registro descrito en el inventario resulta engañoso. Muchos de los registros llevan títulos genéricos, "és de sermons" o "de oficis", que inducen a pensar que estaban escritos en lengua vernácula sin embargo, si en estos casos, aportan el incipit de la obra, como por ejemplo "de oficis, e comença: in consacracione altaris", es indudable que estaba escrita en latín.

En consecuencia, tanto por estas especificaciones como por las identificaciones de los títulos realizadas a partir de diferentes catálogos se puede afirmar que la casi totalidad de los libros que componían la biblioteca estaban escritos en latín, tal como corresponde a un eclesiástico, el resto en lengua vernácula.

\subsubsection{ESCRITURA}

También resulta complicado saber el tipo de letra desarrollada en la elaboración de las obras. Algunos de los libros fueron obra del propio Pere Dorchal pues estaban copiados por él, "scrit de mà del defunt". Lo que no aclara el inventario es si fueron copias de textos conocidos o el resultado de su actividad predicadora. Lo cierto es que, o bien llevado por el interés personal de conseguir determinados títulos o bien por no poseer demasiado dinero para su adquisición, él mismo copió parte de esos libros. Más allá de todo esto solo existe una descripción detallada en el registro [21] "Biblieta en pergamí, molt spessa". Es decir, letra muy prieta que incluso podría dificultar su lectura, pero el tamaño del libro obligaba a adaptarla al espacio, pues eran habituales entre los predicadores las biblias de pequeño tamaño para poder llevarlas con ellos y facilitarles su consulta.

\subsection{DESCRIPCIÓN INTERNA DE LOS LIBROS}

Los títulos que han sido identificados nos indican que es la biblioteca de un predicador, su instrumento de trabajo. Pere Dorchal coincidió en tiempo y espacio con uno de los predicadores más famosos y populares, san Vicent Ferrer. De hecho su muerte se produjo con pocos días de diferencia en 1419, Ferrer el 5 de abril en Vannes (Francia), Dorchal el 26 de abril en Valencia. En lo político los tiempos fueron convulsos: muerte del rey Martín el Humano sin descendencia, Compromiso de Caspe, llegada de la rama real castellana a la Corona de Aragón con la proclamación de Fernando de Antequera como rey (1412-1416) y sucesión en su hijo Alfonso el Magnánimo en 1416. En lo religioso coincidió con el Cisma de Occidente y su final. Esos tiempos convulsos implican una relajación de las costumbres, que obligan a un constante recordar la necesidad del arrepentimiento y la penitencia, además del reconocimiento

${ }^{67}$ Compuesto pastoso formado por harina y agua. 
y acatamiento al poder real. La predicación era la forma propagandística más segura de acatar ese poder, instruir en la fe y fomentar la moral cristiana, junto a la práctica de la oración. Los sermones, en especial, podían tener un carácter penitencial, para pedir el arrepentimiento, disciplinar, recordando los diez mandamientos y devocional, pues los santos eran el modelo a seguir, no sólo como elementos devocionales sino también como ejemplos de lucha constante y superación para afianzar la fe, capaces de abrir las puertas del cielo al intermediar en el Purgatorio. Además, durante la cuaresma el tema predilecto del sermón era la penitencia. Los sermonarios, el ars praedicandi, se hacen necesarios para orientar a los predicadores. Marianne Briscoe ${ }^{68}$ es una de las estudiosas más sobresalientes sobre este tipo de libros y destaca que solían estar escritos en papel, por el propio predicador y en formatos pequeños para ser transportados con facilidad. El predicador solía inspirarse en tratados teológicos, penitenciales, vidas de santos y sagradas escrituras. El sermón solía dividirse en un tema (thema) que partía del Evangelio o de un versículo bíblico. Luego trataba de ganarse la benevolencia de su auditorio para eso solía rezarse un padrenuestro o un avemaría (prothema), a continuación una introducción (introductio) para justificar la elección del tema. Después la división (divisio) en partes que se iban subdividiendo con razonamientos inspirados en metáforas, ejemplos o vidas de santos que se alargaban según la conveniencia del propio predicador. Todo se reforzaba con citas de autores (auctoritates). En definitiva, una lectura sacra con especial incidencia en los salmos, los himnos litúrgicos, hagiografías además de textos patrísticos y teológicos para provocar una reacción en el oyente. En palabras de Albert Toldrà el predicador:

La tasca del predicador consisteix en: traslladar el discurs escrit a oralitat, acostament cultural, apropar el desfasament històric dels textos mitjançant la comprensió i adecuar el codi lingüístic, es a dir, la versió del llatí a la llengua vulgar ${ }^{69}$.

Si todo lo anterior lo centramos en los títulos descritos de la biblioteca de Pere Dorchal, vemos que el primer título recogido en el inventario "la istòria del cavaller que entrà en lo purgatori de sent Patrici" es una excepcionalidad y nos inclinamos a creer que tal vez la copió el propio Dorchal, aunque no diga nada al respecto, por su interés en actualizar sus prédicas en personajes y situaciones políticas convulsas que él vivió como fue el Cisma y el Interregno. Es un libro que, más allá de considerarse "lectura lúdica" está entroncada en todos los temas predicables y propagandísticos del periodo político: pecados, Purgatorio, oración, ayuno, personajes contemporáneos (rey Joan I de Aragón, Francesc Eiximenis).

Después de este título el resto de los que componen el inventario pueden agruparse según la temática de la predicación:

La Biblia, el libro por excelencia de todo eclesiástico, Biblieta.

De carácter devocional íntimo, horetes, junto a otros de recitación colectiva, set psalms, Stimulus amoris, l'ofici de sent Narcís.

Sobre la misa y la formación que todo eclesiástico debe tener sobre ella además de las celebraciones particulares acordes a festividades o actividades especiales, al-

68 BRISCOE, Artes praedicandi, pp. 60-61.

69 TOLDRÀ, "Per peccat se scriu en les calderes de infern", p. 8 
gunos de esos títulos de especial relevancia e ilocalizables en otros inventarios como Johannes Bellot, Liber reponcitorum super tractatum misse, Liber Ymnorum, Super corrempta in missa, Manipulus curatorum, De oficis... 'in consacracione altaris', Misses que's deuen dir en temps de mortalitat.

Otro grupo trata de los pecados y su penitencia, De virtutibus antiquorum, De ymagine mundi, Concordançes dels X manaments, Summa de penitencia de magistro Raymundo dita, De auctoritatibus virtutum et viciorum.

El tema mariano, la Virgen y su asunción como ejemplo de pureza, nobleza, buenas obras, etc. de tanta importancia a tenor de su presencia en todos los inventarios tanto eclesiásticos como laicos aunque en estos últimos suele ser de carácter devocional, Miraculorum luce Marie, Libre de Sent Alifonso[sic] de laude virginis.

Los libros acordes con las directrices de la propia diócesis de Valencia, Constitutiones sinodales ecclesie Valencie, Magna partes libri racionalis, Privilegis de la ciutat, Breviari de consueta de València.

Tampoco faltan los títulos relacionados con las autoridades de la Iglesia y que suponen una formación sacerdotal escolástica, Dialogorum beati Gregorii, Breviloquium Tarentacii super IIII ${ }^{\circ}$ Libris summiarum, Magister Summiarum, Soliloquium Augustini.

También de carácter apocalíptico como uno de los temas predicables, Exposicione apocalipsis, Natura angelica, de maestre[sic] Francesch Eximenez.

Por último la enseñanza de la gramática, Liber compoti et Algracismi.

Es indudable que es una biblioteca especializada en predicación al servicio de un eclesiástico que tiene una buena formación escolástica y que está preparado para ejercerla, aunque su nombre no aparezca entre los predicadores conocidos. Por último, al margen de su biblioteca, también puede ratificar el oficio de predicador de Pere Dorchal la vestimenta eclesial ${ }^{70}$ descrita en su inventario de bienes, pues incluye ropa propia de un predicador como son el amito, amit, y cinco sobrepellices, $V$ sobrepellicos, sotils e tots squincats. Todo ello guardado en un cofre en el comedor, la habitación central de su casa. Una vestimenta que forma parte de una "puesta en escena" necesaria para imbuir mejor el mensaje.

\section{CONCLUSIONES}

En resumen, tiempos de inestabilidad religiosa por el fin del Cisma de Occidente y cambios políticos con la nueva dinastía Trastámara que entraba a reinar en la Corona de Aragón que obligan a los nuevos poderes, real y papal, a usar todos los canales disponibles a su alcance para hacerse oír y alcanzar los fines de estabilidad política y social. La predicación era ese canal propagandístico y de adoctrinamiento imprescindible, lo que llevó a cuidar este aspecto con especial presteza por parte de la jerarquía eclesiástica. La insistencia en los temas predicables de sostenimiento a la Iglesia, a

${ }^{70}$ El presbítero se reviste en la sacristía con siete vestidos: el sobrepelliz, si es simple presbítero o si es obispo el roquete, o si es religioso el escapulario que va en lugar del sobrepelliz. El segundo vestido es el amito. El tercero, el alba. El cuarto, el cíngulo. El quinto, la estola. El sexto, el manípulo. El séptimo, la casulla. EsPonera CERDÁn, El oficio de predicar, p. 110. 
los pobres (en especial a los huérfanos), la moralidad de las costumbres en todos los estamentos de la sociedad junto con el miedo a tiempos venideros de justicia divina, tiempos apocalípticos, se convierten en una constante al servicio de ese poder como única forma de salvación.

Todo ello se ve reflejado en la biblioteca de Pere Dorchal, en ese microcosmos librario. Demuestra que era un predicador de sólida formación eclesiástica basada en el libro por excelencia, la Biblia, junto a todos aquellos libros eclesiásticos necesarios para el ejercicio divino en donde la misa ocupaba el tema central. Es el momento de la actualización de la nueva alianza entre Dios y los hombres a través de signos sacramentales. Una práctica que no había sido lo suficientemente resaltada por los Padres Latinos a excepción de san Agustín pero en el que incidieron diferentes estudiosos a partir del siglo XIII como Jean Beleth, de ahí la importancia de estar incluido este autor entre los libros poseídos por Dorchal y que no aparece entre los títulos de otros inventarios de ámbito eclesiástico en la ciudad de Valencia, no así en Barcelona aunque no fuera hasta después de 1430 , y mucho menos se encuentra entre los inventarios laicos valencianos. Sin embargo la misa también es el acto litúrgico que congrega a mayor número de personas, a los feligreses, por tanto es el momento apropiado para inculcar la palabra de Dios, para adoctrinar, de ahí la importancia de la predicación, de ese canal propagandístico por excelencia.

De los temas elegidos por Dorchal para sus propias predicaciones se pueden intuir a través de la temática de sus libros: exaltación de la Virgen María como guía para una vida de pureza frente a las otras minorías religiosas de la ciudad (judíos y musulmanes). Una devoción fomentada junto a la de otros santos como intermediadores para una vida del más allá que se sabe próxima y que exigía arrepentimiento de los pecados y penitencia continuada. Todo ello como símbolo de los tiempos apocalípticos que se avecinan y que tienen en los vaivenes políticos (cambio dinástico) y religiosos (fin del Cisma de Occidente) un campo abonado para consolidar los nuevos poderes y a los que la jerarquía eclesiástica se somete como canal de transmisión. Temas y actitudes que son precedentes de lo que a partir de mediados del siglo XV se denominará devotio moderna, una práctica devocional más individualizada, de reflexión interior en torno a Cristo y su Pasión. Unas predicaciones ejercidas por Dorchal bajo el prisma de la ortodoxia cristiana de autores como san Gregorio o san Agustín, junto con las directrices establecidas por la propia diócesis valentina y la municipalidad a la que él pertenece como demuestran los títulos que a ese respecto contiene su biblioteca (Consueta, Privilegis, etc.). Sin embargo lo que sobresale de esta biblioteca es la aparición entre sus títulos de La istòria del cavaller que entrà en lo purgatori de sent Patrici, de Ramón de Perellós. Una obra descrita por primera vez en una biblioteca de la ciudad de Valencia. Un título que sólo fue popular en la zona catalana y que, tal vez, Pere Dorchal conociera por su pertenencia a la cofradía de Sent Narcís, fundada en Valencia por mercaderes gerundenses. Una obra de autor y personajes contemporáneos a Pere Dorchal y que incide en los elementos y temas predicables: monarquía, Purgatorio, penitencia, oración. Una posesión excepcional no valorada por el canónigo investigador Sanchis Sivera a pesar de conocer el inventario. Una biblioteca profesional que transmite la cosmovisión de una Valencia del Interregno. Al mismo tiempo Pere Dorchal representa la vida crediticia practicada en 
la ciudad durante los siglos XIV-XV con sus consecuencias sociales como la abundancia de pobres vergonyants.

En definitiva un propietario que ha de compaginar la vida sacerdotal con tareas administrativas privadas para poder subsistir, como lo demuestra la posesión del libro racional o la gestión de fondos de òrfenes a maridar, esto último sólo permitido a burgueses y a la que tuvo acceso por su posible ascendente familiar mercantil que, a su vez, le permitió su ingreso en la prestigiosa cofradía de Sent Narcís de tanta influencia social y política en Valencia.

\section{BIBLIOGRAFÍA}

Aventin Puig, Mercè, "Mercat de rendes, mercat de salvació" en Manuel Sánchez Martínez (comp.), Estudios sobre renta, fiscalidad y finanzas en la Cataluña Bajomedieval, Barcelona: Institución Milà i Fontanals, 1993, pp. 133-151.

Briscoe, Marianne, Artes praedicandi, Turnhout: Brepols, 1992.

ESPONERA CERDÁn, Alfonso, El oficio de predicar: los postulados teológicos de los sermones de san Vicente Ferrer, Salamanca: San Esteban, 2007.

Ferrer Gimeno, Ma Rosario, La lectura en Valencia (1416-1474): una aproximación histótica [Tesis doctoral inédita], Valencia: Universitat de València, 1993.

Gallent Marco, Mercedes, "Sanidad y urbanismo en la Valencia del XV", En la España medieval, 7 (1985), pp. 1567-1580.

García Marsilla, Juan Vicente, Vivir a crédito en la Valencia medieval: de los orígenes del sistema censal al endeudamiento del municipio, València: Universitat de València, 2002.

Gimeno Blay, Francisco, La escritura en la diócesis de Segorbe: una aproximación al estudio del alfabetismo y la cultura escrita en el Alto Palancia (1383-1458), [Tesis doctoral inédita], Valencia: Universitat de València, 1984, 2 vols.

Gimeno Blay, Francisco, El Compromiso de Caspe (1412): diario de un proceso. Zaragoza: Institución Fernando el Católico, 2012.

Hillgarth, Jocelyn Nigel, Readers and Books in Majorca 1229-1550, Paris: Centre National de la Recherche Scientifique, 1991, 2 vols.

Hinojosa Montalvo, José, "Aportaciones a la bibliología valenciana durante el reinado de Alfonso El Magnánimo”, Ligarzas, 7, (1975), pp. 213-228.

IgLeSIAS I FonseCA, Josep Antoni, Llibre i lectors a la documentació notarial (1396-1475), [Tesis doctoral inédita], Barcelona: Universitat de Barcelona, 1996, 2 vols.

Llanes i Domingo, Carme, L'obrador de Pere Nicolau i la segona generació de pintors del gòtic internacional a València, [Tesis doctoral inédita], Valencia: Universitat de València, 2011.

MADURell I MARIMON, Josep Ma , Manuscrits en català anteriors a la impremta (1321-1474): contribució al seu estudi. Barcelona: ANABAD, 1974.

Marquès, Josep Ma "El temple de Sant Feliu de Girona, al s.XIV", Annals de l'Institut d'Estudis Gironins, XLII (2001), pp. 131-150.

Metge, Bernat, Lo somni, Barcelona: Barcino, 2006. 
Munsuri, M ${ }^{\mathrm{a}}$ Nieves, Perspectiva socio-económica del clero secular en la Valencia del siglo $X V$, [Tesis doctoral inédita], València: Universitat de València, 1999, 2 vols.

Orellana, Marcos Antonio de, Valencia antigua y moderna, Valencia: Acción Bibliográfica Valenciana, 1924, 2 vols.

Pons Alós, Vicente, Cárcel Ortí, Ma Milagros, "La diócesis de Valencia durante los pontificados de los Borja", Anales valentinos: revista de filosofía y teología, $27: 53$ (2001), pp. 87-120.

Rius Serra, José, "Inventario de manuscritos de la catedral de Sigüenza”, Hispania sacra, 3:6 (1950), pp. 431-465.

Rivera Garretas, María-Milagros, “Una vida en relación: Juana de Mendoza”, en Ana del Campo Gutiérrez...[et al.] (eds.), Vidas de mujeres del Renacimiento, Barcelona: Universidad de Barcelona, 2007.

Roca Traver, Francisco, "Interpretación de la cofradía valenciana: la Real Cofradía de San Jaime", Estudios medievales, 2:2 (1957), pp. 37-83.

Rubio Vela, Agustín, “Infancia y marginación: en torno a las instituciones trecentistas valencianas para el socorro de los huérfanos", Revista d'historia medieval, 1 (1990), pp. 111-153.

Rubio Vela, Agustín (ed.), Epistolari de la València medieval, I, València: Institut Interuniversitari de Filologia Valenciana, 2003.

SAENGER, Paul, "Books of Hours and Reading Habits of the Middle Ages" en Roger Chartier (ed.), The Culture of Print: power and the uses of print in Early Modern Europe, Princeton: Princeton University Press, 1989.

SANCHIS Sivera, Josep, Estudis d'història cultural, València [etc.]: Institut Interuniversitari de Filologia Valenciana [etc.], 1999.

TOLDRÀ, Albert, "Per peccat se scriu en les calderes de infern: llibre i escriptura al Més Enllà medieval", Signo: revista de historia de la cultura escrita, 11 (2003), pp. 7-36.

\section{Catálogos}

FAUCON, Maurice, La librairie des papes d'Avignon: sa formation, sa composition, ses catalogues, 1316-1420, Amsterdam: Gérard van Heusen, 1969.

Jorgensen Concheff, Beatrice, Bibliography of Old Catalan Texts, Madison: Hispanic Seminary of Medieval Studies, 1985.

Lilao Franca, Óscar [et al.] (eds.), Catálogo de manuscritos de la Biblioteca Universitaria de Salamanca, Salamanca: Universidad de Salamanca, 2002, 2 vols.

López de Toro, José, PAz Remolar, Ramón (eds.), Inventario general de manuscritos de la Biblioteca Nacional, Madrid: Dirección General de Archivos y Bibliotecas, 1953-2000, 14 vols.

Massó I Torrents, Jaume, Rubió I BALAGuer, Jordi, Catàleg dels manuscrits de la Biblioteca de Catalunya, Barcelona: Biblioteca de Catalunya, 1989-

Olmos Canalda, Elías, Catálogo descriptivo de los códices de la Catedral de Valencia, Valencia: Tipografía Moderna, 1943. 